\title{
Morfoanatomia, histoquímica e perfil fitoquímico de Priva lappulacea (L.) Pers. (Verbenaceae)
}

\author{
Jovita Maria de Farias Braga,${ }^{1}$ Rejane Magalhães de Mendonça Pimentel, ${ }^{*}, 2$ Clébio Pereira Ferreira,${ }^{2}$ Karina \\ Perrelli Randau, ${ }^{1}$ Haroudo Satiro Xavier ${ }^{l}$ \\ ${ }^{1}$ Laboratório de Farmacognosia, Departamento de Ciências Farmacêuticas, Universidade Federal de \\ Pernambuco, 50740-521 Recife-PE, Brasil, \\ ${ }^{2}$ Laboratório de Fitomorfologia Funcional, Departamento de Botânica, Universidade Federal Rural de \\ Pernambuco, Dois Irmãos, 52171-900 Recife-PE, Brasil
}

\begin{abstract}
RESUMO: Este estudo descreve a anatomia e analisa a histoquímica dos órgãos vegetativos de Priva lappulacea (L.) Pers. Secções transversais e paradérmicas, à mão livre, de material fresco e fixado foram utilizadas para as análises anatômicas e histoquímicas, usando microscopia óptica. Os caracteres anatômicos são comuns àqueles descritos para a família, podendo ser utilizados como diagnóstico na sua identificação. Destacam-se, nas folhas, os tricomas, glandular e não-glandular, estômatos anomocíticos, em ambas as faces da epiderme, e mesofilo dorsiventral. As expansões no pecíolo são acrescentadas à diagnose da espécie. Estudo fitoquímico realizado com as partes aéreas mostrou a presença de triterpeno (ácido ursólico) e esteróide ( $\beta$-sitosterol), iridóides (ipolamida e catalpol), açúcar redutor (glucose), flavonóide (luteolina) e fenilpropanóide (verbascosídeo). Nas raízes foi encontrada apenas glucose e dois iridóides estiveram presentes no caule e folhas. Alcalóides, saponinas, cumarinas, derivados cinâmicos, proantocianidinas condensadas e leucoantocianidinas não foram constatados nas partes analisadas. A descrição anatômica e os testes histoquímicos são inéditos para P. lappulacea.
\end{abstract}

Unitermos: Priva lappulacea, Verbenaceae, morfoanatomia, perfil fitoquímico.

\begin{abstract}
Morphoanatomy, histochemistry and phytochemical screening of Priva lappulacea (L.) Pers. (Verbenaceae)". This study describes the anatomy and analyzes the histochemistry of the vegetative organs of Priva lappulacea (L.) Pers. Freehanded transversal and paradermal sections of fresh and fixed material were used for the anatomical and histochemical analyses, using optical microscopy. The anatomical characters are common to those described for the family, being able to be used to diagnosis in its identification. The leaves are highlighted by the presence of glandular and non-glandular trichomes, anomocytic stomata on both faces of the epidermis and dorsiventral mesophyll. The expansions in the petiole are added to the diagnosis of this species. The phytochemical study carried out with aerial organs showed the presence of triterpene (ursolic acid) and steroid ( $\beta$-sitosterol), iridoids (ipolamide and catalpol), reducing sugar (glucose), flavonoid (luteolin) and fenilpropanoid (verbascosides). In the roots only glucose was found and two iridoids are present in stem and leaves. Alkaloids, saponins, cumarines, cinamic acid derivates, condensed proantocianidines and leucoantocianidines were not checked in the analyzed parts. The anatomical description and the histochemical tests are unpublished for P. lappulacea.
\end{abstract}

Keywords: Priva lappulacea, Verbenaceae, morphoanatomy, phytochemical screening.

\section{INTRODUÇÃOO}

A família Verbenaceae está constituída de, aproximadamente, 100 gêneros e 2600 espécies (Cronquist, 1981) ocorrendo em regiões temperadas, tropicais e subtropicais de ambos os hemisférios (Bonzani et al., 2003). Seus representantes apresentam hábito variado, desde árvores de grande porte (Tectoma grandis L.) até ervas (Verbena officinalis L.) (Metcalfe \& Chalk, 1972).

O gênero Priva possui cerca de vinte representantes, dois ocorrentes no Brasil. No nordeste do Brasil a espécie Priva lappulacea é conhecida popularmente como "carrapicho" e "pega-pega", devido às suas características pegajosas, sendo citada na literatura como vermífuga (Metcalfe \& Chalk, 1972).

Entre as dicotiledôneas que contêm princípios aromáticos, a família Verbenaceae se destaca por ter alguns de seus representantes utilizados na medicina popular por suas propriedades digestivas (Bonzani et al., 2003; Agra et al., 2007; 2008; Leitão et al., 2009), antidiabética (Dornas 
et al., 2009) antimalárica (Froelich et al., 2008: Mariath et al., 2009), antiúlcera e antiinflamatória (Jesus et al., 2009), em odontologia (Oliveira et al., 2007), em cosmética (Biavatti et al., 2007) e por sua importância, algumas são citadas na Farmacopéia Brasileira (Brandão et al., 2006; 2008; 2009).

Segundo Metcalfe e Chalk (1972), as folha de espécies de Verbenaceae, incluindo Priva echinata Juss., são utilizadas no preparo de chás.

Investigações acerca da anatomia da família Verbenaceae têm enfatizado algumas espécies, sem qualquer citação para representantes do gênero Priva. Espécies pertencentes ao gênero Lippia foram mais extensamente investigadas quanto a determinação de seus constituintes químicos (Costa et al., 2002) e sua comprovada ação antiinflamatória (Pérez et al., 2005), antimicrobiana (Kunle et al., 2003; Aguiar et al., 2008), efeito colerético e efeito antiespasmódico (Gorzalczany et al., 2008) e anticonvulsivante (Quintans-Júnior et al., 2008). Poucos estudos químicos foram descritos em $P$. lappulacea; na literatura registra-se apenas a identificação dos iridóides ipolamida e catalpol (Mulert, 2001).

O objetivo deste estudo foi descrever a estrutura anatômica dos órgãos vegetativos (raiz, caule e folha) de Priva lappulacea (L.) Pers., visando identificar caracteres auxiliares no diagnóstico desta espécie e ampliar o conhecimento da anatomia dos representantes da família Verbenaceae que ocorrem no nordeste do Brasil. Além disso, uma análise fitoquímica e testes histoquímicos foram realizados para a verificação da presença de metabólitos secundários e os locais de sua ocorrência na planta.

\section{MATERIAL E MÉTODOS}

Amostras de raiz e partes aéreas (caule e folhas) de Priva lappulacea (L.) Pers. foram coletadas no Campus da Universidade Federal de Pernambuco (UFPE), em Recife, Pernambuco, Brasil, de diferentes indivíduos ocorrendo naturalmente. O material testemunho foi depositado no Herbário Dárdano de Andrade Lima (IPA-
Empresa Pernambucana de Pesquisas Agropecuária) (IPA - 70200). A identificação da espécie foi realizada através de comparações morfológicas com descrições de Kobuski (1926), em revisão do gênero Priva.

Material botânico, fresco e fixado em FAA 50 (Johansen, 1940) foi usado para a análise anatômica. Lâminas semipermanentes foram produzidas com secções transversais, à mão livre, da raiz, caule e porção mediana do pecíolo e lâmina foliar, na região mediana da nervura principal. Fragmentos epidérmicos, de ambas as faces foliares, foram obtidos após dissociação, por imersão em solução de hipoclorito de sódio a $20 \%$, por $48-72$ horas. As amostras foram coradas com safranina (solução alcoólica) $1 \%$, azul de astra (solução aquosa) $1 \%$ e azul de metileno (solução aquosa) 1\%, com montagem em glicerina aquosa 50\% (Krauter, 1996).

Secções de material fresco foram submetidas a testes histoquímicos para a identificação dos grupos de metabólitos: alcalóides, amido, compostos fenólicos diversos, lignina e lipídeos nos órgãos vegetativos de $P$. lappulacea, seguindo as indicações contidas nas referências listadas na Tabela 1. As reações foram acompanhadas e fotografadas sob microscopia óptica de luz visível.

Imagens digitais das secções histológicas, dos diferentes órgãos vegetativos da espécie em estudo, foram produzidas sob microscópio óptico (Olympus) acoplado com câmera digital (Sony W5). As escalas e numerações foram inseridas utilizando-se imagens de lâmina micrométrica, obtidas sob condições idênticas àquelas utilizadas para a confecção das imagens das secções histológicas e programa Photoshop, versão 7.0 (Adobe Systems). As terminologias utilizadas neste estudo seguiram Metcalfe \& Chalk (1972 e 1988) e a classificação dos estômatos de acordo com Baranova (1987).

O perfil fitoquímico foi realizado através de extratos metanólicos das partes aéreas. Os extratos foram analisados por cromatografia em camada delgada (cromatoplacas de gel de sílica Merck-Alemanha), empregando-se diversas fases móveis e reveladores adequados, de acordo com a metodologia descrita na Tabela 2 .

Tabela 1. Testes histoquímicos realizados nos órgãos vegetativos de Priva lappulacea (L.) Pers. (Verbenaceae).

\begin{tabular}{lll}
\hline \multicolumn{1}{c}{ Grupos de Metabólitos } & Luz visível & Referência \\
\hline Alcalóides & Dragendorff & Furr \& Mahlberg, 1981 \\
& Reagente de Wagner & Wagner \& Bladt, 1996 \\
Amido & Lugol & Johansen, 1940 \\
Compostos Fenólicos Gerais & Cloreto férrico & Johansen, 1940 \\
Lignina & Floroglucinol acidificado & Johansen, 1940 \\
Lipídeos & Sudan III & Sass, 1951 \\
Taninos & & Vanilina clorídrica \\
\hline
\end{tabular}


Tabela 2. Sistemas cromatográficos e reveladores utilizados para o perfil fitoquímico de Priva lappulacea (L.) Pers. (Verbenaceae).

\begin{tabular}{|c|c|c|c|}
\hline Metabólitos & Sistemas de eluição & Reveladores & Referência \\
\hline Alcalóides & $\begin{array}{l}\text { AcOEt- } \mathrm{HCOOH}-\mathrm{AcOH}-\mathrm{H}_{2} \mathrm{O} \\
(100: 11: 11: 26 \mathrm{v} / \mathrm{v})\end{array}$ & Dragendorff & Wagner \& Bladt, 1996 \\
\hline $\begin{array}{l}\text { Triterpenóides e } \\
\text { Esteróides }\end{array}$ & $\begin{array}{l}\text { AcOEt-HCOOH-AcOH- } \mathrm{H}_{2} \mathrm{O} \\
(100: 0,5: 0,5: 0,5 \mathrm{v} / \mathrm{v})\end{array}$ & Lieberman/Burchard & Harborne, 1998 \\
\hline Iridóides & $\begin{array}{l}\text { AcOEt-HCOOH-AcOH- } \mathrm{H}_{2} \mathrm{O} \\
(100: 11: 11: 27 \mathrm{v} / \mathrm{v})\end{array}$ & Vanilina sulfúrica & Wagner \& Bladt, 1996 \\
\hline Saponinas & $\begin{array}{l}\text { AcOEt-HCOOH-AcOH- } \mathrm{H}_{2} \mathrm{O} \\
(100: 11: 11: 27 \mathrm{v} / \mathrm{v})\end{array}$ & Vanilina sulfúrica & Wagner \& Bladt, 1996 \\
\hline Açúcares redutores & $\begin{array}{l}n \text {-BuOH-Me2CO- Tampão } \\
\text { fosfato } \mathrm{pH}=5,0(40: 50: 10 \mathrm{v} / \mathrm{v})\end{array}$ & Trifeniltetrazólio & Metz, 1961 \\
\hline Cumarinas & Éter-tolueno-AcOH 10\% & U. V. (365 nm) & Wagner \& Bladt,1996 \\
\hline Derivados cinâmicos & $\begin{array}{l}\text { AcOEt-HCOOH-AcOH- } \mathrm{H}_{2} \mathrm{O} \\
(100: 11: 11: 27 \mathrm{v} / \mathrm{v})\end{array}$ & NEU & $\begin{array}{l}\text { Wagner \& Bladt,1996; } \\
\text { Neu, } 1956\end{array}$ \\
\hline Flavonóides & $\begin{array}{l}\text { AcOEt-HCOOH-AcOH- } \mathrm{H}_{2} \mathrm{O} \\
(100: 11: 11: 27 \mathrm{v} / \mathrm{v})\end{array}$ & NEU & $\begin{array}{l}\text { Wagner \& Bladt,1996; } \\
\text { Neu, } 1956\end{array}$ \\
\hline Fenilpropanoglicosídeos & $\begin{array}{l}\text { AcOEt-HCOOH-AcOH- } \mathrm{H}_{2} \mathrm{O} \\
(100: 11: 11: 27 \mathrm{v} / \mathrm{v})\end{array}$ & NEU & Wagner \& Bladt, 1996 \\
\hline $\begin{array}{l}\text { Proantocianidinas } \\
\text { condensadas e }\end{array}$ & $\begin{array}{l}\text { AcOEt-HCOOH-AcOH- } \mathrm{H}_{2} \mathrm{O} \\
(100: 11: 11: 27 \mathrm{v} / \mathrm{v})\end{array}$ & Vanilina clorídrica & Roberts et al., 1957 \\
\hline Leucoantocianidinas & & & \\
\hline
\end{tabular}

\section{RESULTADOS}

Priva lappulacea, uma erva daninha perene, quase cosmopolita, com caule em haste decumbente ou procumbente, geralmente tetragonal; folhas opostas, cruzadas, com gemas axilares, lanceoladas, pecíolo delgado e piloso; lâmina foliar membranosa, oval e serrilhada, geralmente subtruncada ou subcordada (ou aguda quando jovem) na base, pilosa em ambas as faces (Wiggins e Porter, 1971 citados em Hawaiian Ecosystems at Risk Project, 2006).

A raiz de $P$. lappulacea (Figura 1), em estrutura primária, está revestida por epiderme uniestratificada, com células cobertas por cutícula delgada e exoderme com paredes fracamente lignificadas. O córtex, em estrutura secundária, é revestido por periderme, composta por súber, felogênio e feloderme, sem distinção entre córtex externo e interno (Figura 2). Idioblastos presentes no córtex radicu- lar, em estrutura primária e secundária, consistem de células arredondadas, repletas de pequenas drusas de oxalato de cálcio (Figura 2). O córtex é limitado internamente por uma endoderme constituída por uma única camada de células.

$\mathrm{O}$ caule tem contorno quadrangular e medula ocupando uma área extensa, constituída por células parenquimáticas com paredes delgadas, sendo oca na porção central (Figura 3). Está revestido por epiderme semelhante àquela da raiz, imediatamente seguida por várias camadas de colênquima angular, especialmente nas regiões angulares (Figura 4). É observada a presença de estômatos anomocíticos projetados acima do nível das demais células da epiderme. No córtex são encontrados pequenos grupos isolados de fibras sobre a região do floema (Figura 4). O caule é eustélico, com sistema vascular fechado e colateral, único e contínuo. 

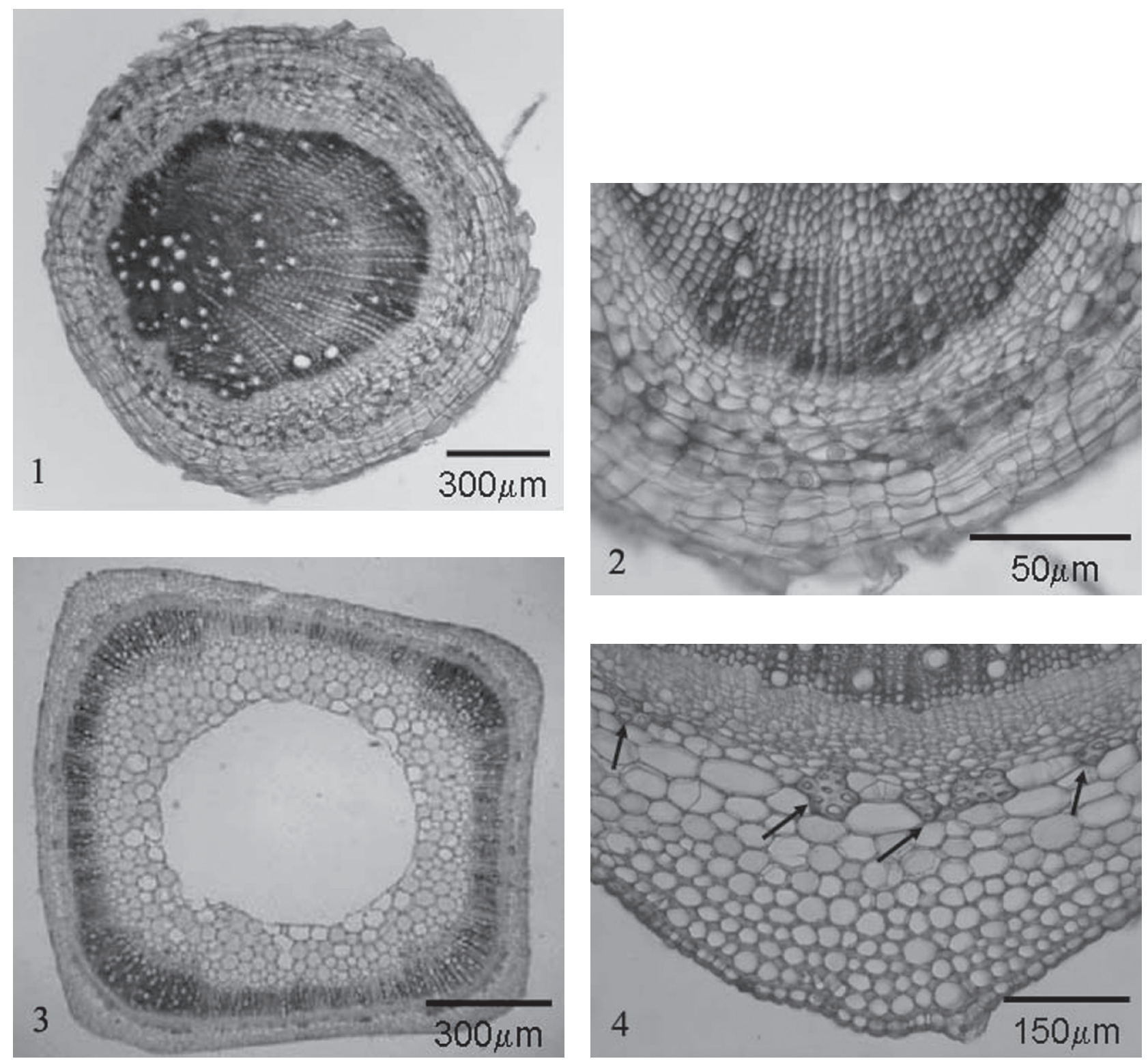

Figuras 1-4. Priva lappulacea (L.) Pers. Verbenaceae: 1. Raiz em secção transversal; 2. Córtex radicular; 3. Caule em secção transversal; 4. Colênquima angular no córtex caulinar e grupos de fibras sobre o floema (setas).

A folha apresenta pecíolo de contorno circular, em vista transversal, com duas projeções laterais arredondadas, projetadas para a face adaxial da lâmina foliar (Figura 5). A epiderme que recobre a face abaxial do pecíolo, incluindo as projeções arredondadas laterais, apresenta inúmeros tricomas tectores e glandulares (Figura 5). Imediatamente abaixo da epiderme existem cerca de duas camadas de colênquima do tipo angular contornando todo o pecíolo. Os tricomas glandulares são semelhantes àqueles encontrados no caule e estão encimados por uma ou duas células vesiculares; a base dos tricomas tectores está constituída por células situadas em um nível acima das demais células da epiderme (Figura 6). Em vista transversal, o feixe vascular mediano tem forma de arco crescente do tipo aberto e está constituído por dois grupos de feixes vasculares colaterais descontínuos (Figura 5). A região descontínua entre os feixes é preenchida por parênquima. Em cada projeção arredondada existe um feixe vascular subsidiário do tipo colateral (Figura 6).

A lâmina foliar, em vista transversal, está revestida por epiderme unisseriada, com células cobertas por cutícula delgada; estômatos anomocíticos estão presentes em ambas as faces (Figuras 7 e 8), ligeiramente projetados acima do nível das demais células da epiderme, semelhante ao que ocorre no caule. Os estômatos se apresentaram em maior número e menores tamanhos na face abaxial, quando comparados àqueles observados na face adaxial (Figuras $7 \mathrm{e} 8$ ).

$\mathrm{Na}$ lâmina foliar são encontrados tricomas 
tectores e glandulares exclusivamente sobre a região da nervura principal (Figura 9), do mesmo modo que tricomas glandulares são exclusivos e esparsos sobre o limbo foliar. Tricomas conoidais (Figura 10) são vistos na região da costela inferior da nervura principal. Os tricomas glandulares estão constituídos por duas células pedunculares curtas, encimadas por duas células vesiculares arredondadas (Figura 11).
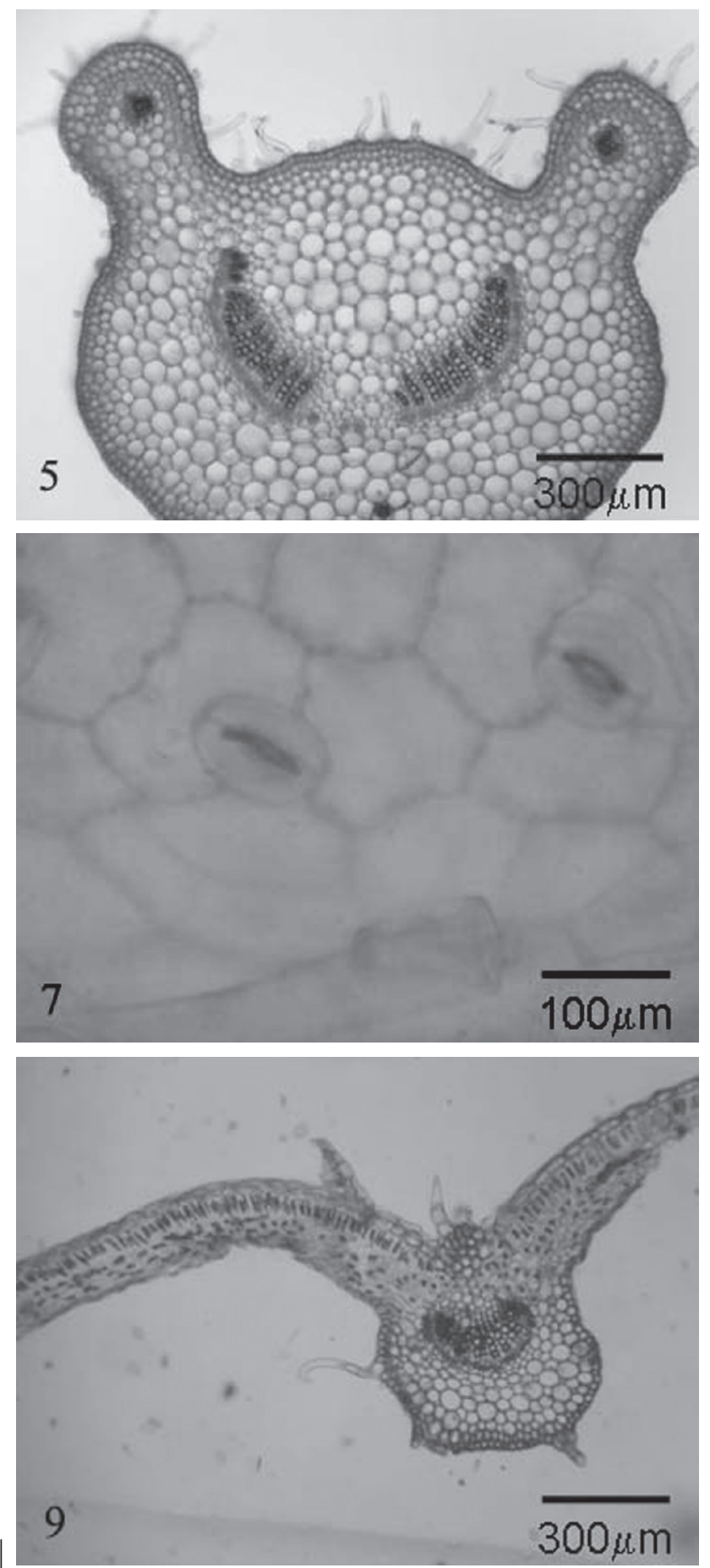

A simetria do mesofilo é dorsiventral, constituído por uma camada de parênquima paliçádico e três camadas de parênquima esponjoso; o paliçádico ocupa cerca de $50 \%$ da espessura do mesofilo (Figura 9).

A nervura principal, na porção mediana da lâmina foliar, apresenta secção transversal biconvexa (Figura 9), com feixe vascular colateral em forma de arco crescente aberto, aparentemente sem fibras constituindo o feixe.
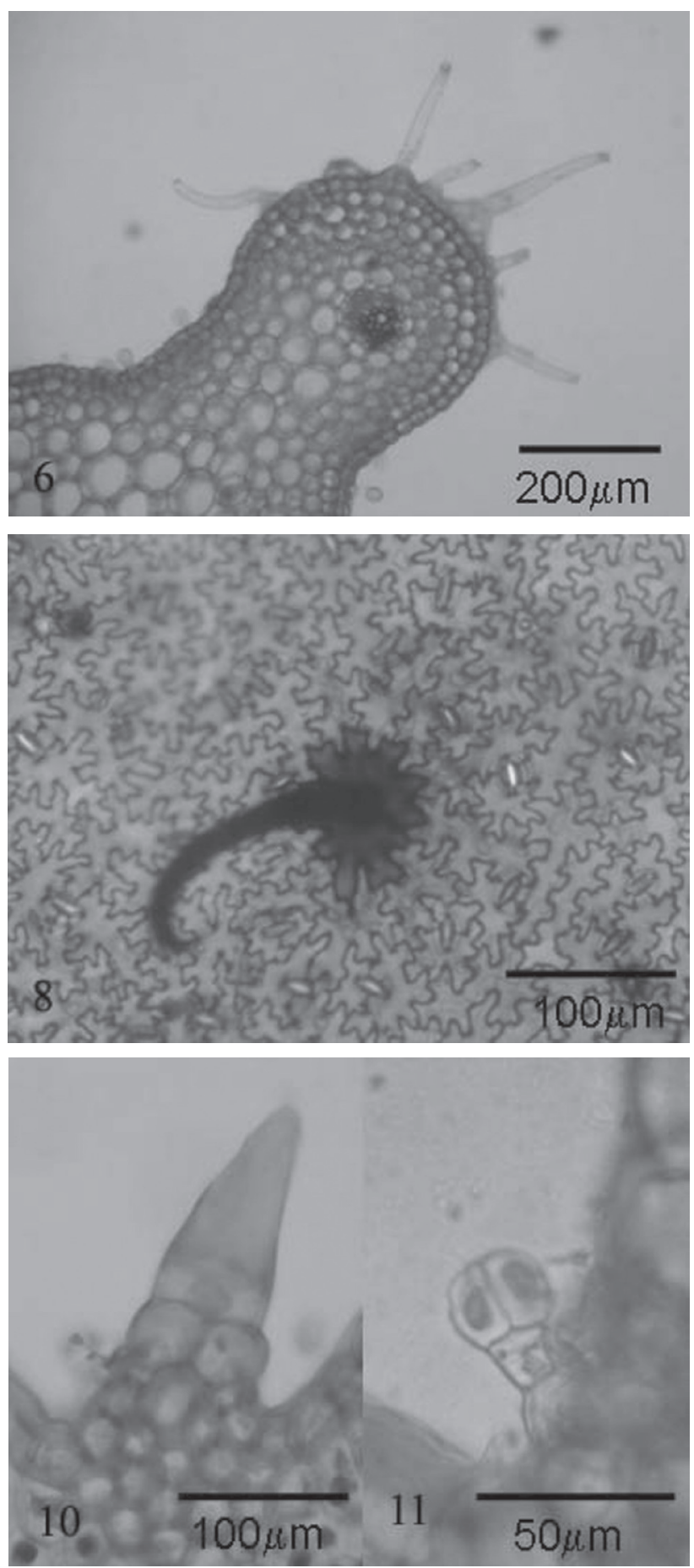

Figuras 5-11. Priva lappulacea (L.) Pers., Verbenaceae: 5. Pecíolo em secção transversal; 6. Detalhe da projeção arredondada do pecíolo; 7 e 8 . Vista frontal da epiderme foliar nas faces adaxial e abaxial, respectivamente; 9. Vista transversal da folha, mostrando a nervura principal e mesofilo dorsiventral; 10 e 11. Tricomas foliares, conoidal e glandular, respectivamente. 
$\mathrm{Na}$ caracterização histoquímica, os testes com os reagentes de Dragendorff e Wagner foram negativos. A coloração azul-negra indicou a presença de amido no clorênquima encontrado no córtex radicular (Figura 12), pecíolo (Figura 13) e mesofilo. A presença de compostos fenólicos gerais foi evidenciada depositada sobre as paredes das células do súber e do parênquima cortical da raiz (Figura 14), nas paredes do clorênquima caulinar e foliar, incluindo a região das expansões do pecíolo (Figura 15). A cor vermelha nas paredes das células de xilema indicou a presença de lignina em elementos de condução do xilema e fibras, em todos os órgãos estudados. Foi observada uma fraca lignificação em grupos de fibras sobre a região do floema no feixe vascular do caule (Figura 16), destacando-se a aparente ausência de fibras constituindo o feixe vascular do pecíolo (Figura 17). A aplicação do Sudan III evidenciou a presença de lipídeos, cutina e suberina, através da coloração amarelo-alaranjada na cutícula, especialmente no caule, no clorênquima, com destaque nas projeções do pecíolo, no súber e córtex radicular (Figura 18), e no parênquima cortical do caule. Quanto à presença de taninos, foi detectada uma coloração cinza na cutícula, nas paredes dos elementos de condução do xilema e nas camadas mais externas do súber radicular.
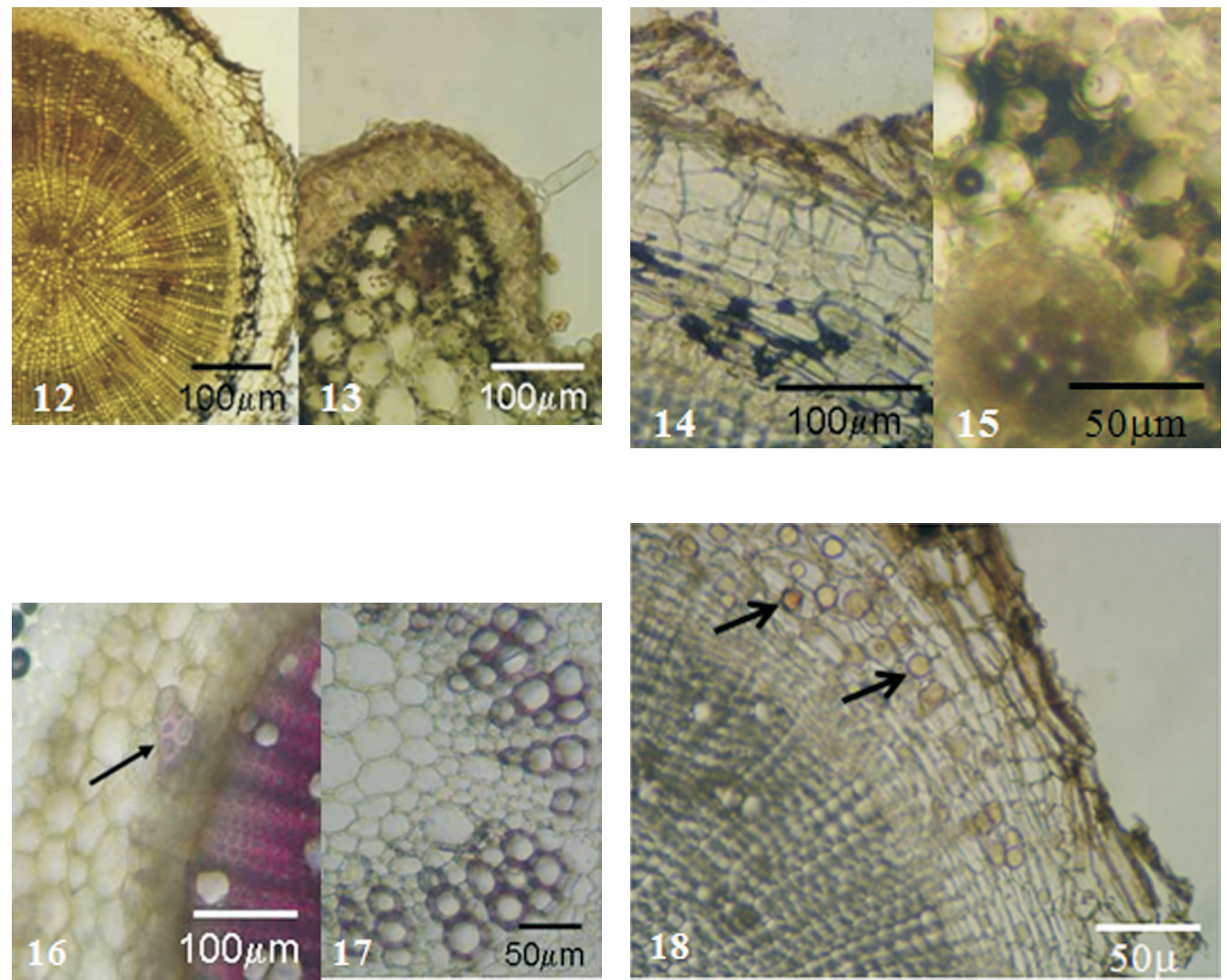

Figuras 12-18. Caracterização histoquímica de Priva lappulacea (L.) Pers., Verbenaceae: 12. e 13. Amido no córtex radicular e projeção lateral do pecíolo, respectivamente; 14 e 15. Compostos fenólicos na feloderme radicular e clorênquima do pecíolo, respectivamente; 16 e 17. Lignina nas paredes dos elementos de xilema e fibras no caule e nos elementos de condução do xilema na nervura principal, respectivamente; 18. Gotículas de compostos graxos de cadeia longa (cutina, suberina e outros lipídios) no parênquima cortical radicular (setas). 
O ensaio fitoquímico evidenciou a presença de triterpenos e esteróides, iridóides, açúcares, flavonóides e fenilpropanóides no caule e folhas. Permitiu, ainda, a identificação de $\beta$-sitosterol, ácido ursólico, ipolamida, catalpol, verbascosídeo e luteolina. Não foi detectada a presença de alcalóides, saponinas, cumarinas, derivados cinâmicos, proantocianidinas condensadas e leucoantocianidinas, sendo os iridóides assinalados as únicas substâncias detectadas nas raízes.

\section{DISCUSSÃO}

Com base nas observações anatômicas realizadas em Priva lappulacea foi verificado que muitas das estruturas são comuns àquela descritas para a família, de modo que estas características podem ser utilizadas como caracteres diagnóstico na identificação desta espécie. Segundo Metcalfe \& Chalk (1972 e 1988), dentre estes caracteres se destacam aqueles observados nas folhas, como os tipos de tricomas, glandular e não-glandular, e o mesofilo dorsiventral. Além disso, todas as descrições acerca da morfologia foliar não se referem às expansões existentes no pecíolo, que se constituem em um importante caractere que pode ser acrescentado à diagnose da espécie.

Em Lippia alba, Ferreira et al. (2003) observou tricomas tectores, quase sempre unicelulares, e tricomas glandulares sésseis ou com pedicelo muito curto, encimando cabeças glandulosas, uni ou pluricelulares, neste último caso, geralmente bicelular, similar àquele encontrado na espécie em estudo.

Os estômatos são encontrados em ambas as faces foliares nas espécies de Priva (Metcalfe \& Chalk, 1972). Todos os estômatos observados nesta espécie são anomocíticos (Figuras 7 e 8), concordando com a descrição apresentada por Baranova (1987), Metcalfe \& Chalk (1988) e Van Cotthem (1970) para este tipo de estômato. Esta classificação está baseada na topografia e disposição das células em torno das células guarda, sem relação com a ontogenia do aparelho estomático. Metcalfe \& Chalk (1988) afirmaram que na família Verbenaceae podem ser encontrados estômatos anomocíticos, paracíticos anisocíticos e diacíticos. Entretanto, em P. lappulacea foram observados apenas estômatos do tipo anomocítico. Segundo Metcalfe \& Chalk (1988), a classificação do tipo de estômato tem grande importância taxonômica.

Foi realizada uma comparação entre os resultados da histoquímica e da fitoquímica. Constatou-se a presença de taninos histoquimicamente, mas não fitoquimicamente. Isto pôs em evidência a possibilidade de um resultado falso-positivo para taninos nos ensaios histoquímicos, uma vez que a cromatografia em camada delgada é um método mais sensível para a detecção dos metabólitos. Assim, quando o reagente utilizado foi o cloreto férrico, o mesmo agiu sobre os taninos e diversos outros fenóis existentes nas células (Kraus \& Arduin 1997). Por outro lado, quando o reagente utilizado foi a vanilina clorídrica, observouse a coloração das células. No perfil fitoquímico não foi evidenciado tanino, concluindo, assim, que os metabólitos corados com a vanilina clorídrica foram os iridóides e não os taninos, uma vez que esse revelador reage também com iridóides. Este resultado contribuiu para a localização dos iridóides nas paredes dos elementos de condução do xilema e nas camadas mais externas do súber radicular.

Em relação a todos os outros testes histoquímicos, todos se mostraram fidedignos quando comparados ao perfil fitoquímico.

Quimicamente, ainda foi caracterizada, por cocromatografia (usando-se padrões), a presença de luteolina (flavona) e verbascosídeo (glicosídeo de fenilpropanóide); estas são substâncias conhecidas que estão sendo descritas, pela primeira vez, para o táxon em questão. O verbascosídeo e a luteolina são compostos largamente encontrados nos vegetais que apresentam atividade antibacteriana e antifúngica. A presença dos iridóides (aqui isolados e caracterizados por métodos físicos) é mais interessante por estar restrita a determinados grupos de vegetais e por estes apresentarem uma gama de atividades farmacológicas, especialmente antiinflamatória.

\section{REFERÊNCIAS}

Agra MF, França PF, Barbosa-Filho JM 2007. Synopsis of the plants known as medicinal and poisonous in Northeast of Brazil. Rev Bras Farmacogn 17: 114-140.

Agra MF, Silva KN, Basílio IJLD, França PF, Barbosa-Filho JM 2008. Survey of medicinal plants used in the region Northeast of Brazil. Rev Bras Farmacogn 18: 472-508.

Aguiar JS, Costa MCCD, Nascimento SC, Sena KXFR 2008. Atividade antimicrobiana de Lippia alba (Mill.) N. E. Brown (Verbenaceae). Rev Bras Farmacogn 18: 436440

Biavatti M, Marensi V, Leite SN, Reis A 2007. Ethnopharmacognostic survey on botanical compendia for potential cosmeceutic species from Atlantic Forest. Rev Bras Farmacogn 17: 640-653.

Bonzani NE, Filippa EM, Barboza GE 2003. Estudio anatómico comparativo de tallo en algunas especies de Verbenaceae. Anales del Instituto de Biología, Universidad Nacional Autónoma de México, Serie Bot 74: 31-45.

Brandão MGL, Cosenza GP, Moreira RA, Monte-Mor RLM 2006. Medicinal plants and other botanical products from the Brazilian Official Pharmacopoeia. Rev Bras Farmacogn 16: 408-420.

Brandão MGL, Zanetti NNS, Oliveira GRR, Goulart LO, MonteMor RLM 2008. Other medicinal plants and botanical products from the first edition of the Brazilian Official Pharmacopoeia. Rev Bras Farmacogn 18: 127-134.

Brandão MGL, Cosenza GP, Grael CFF, Monte-Mór RLM 2009. Traditional uses of American plant species from the 1st edition of Brazilian Official Pharmacopoeia. Rev Bras Farmacogn 19: 478-487.

Costa SMO, Lemos TLG, Deusdênia O, Pessoa L, Assunção JCC, Braz-Filho R 2002. Constituintes químicos de Lippia sidoides (Cham.) Verbenaceae. Rev Bras Farmacogn 12: 66-67. 
Cronquist A 1981. An integrated system of classification of flowering plants. Columbia University Press, New York.

Dornas WC, Oliveira TT, Dores RGR, Fabres MHA, Nagem TJ 2009. Efeitos antidiabéticos de plantas medicinais. Rev Bras Farmacogn 19: 488-500.

Ferreira JLP, Velasco E, Araújo RB, Kuster RM, Amaral ACF 2003. Estudo morfo-anatômico entre os caules de Lippia alba e Melissa officinalis. Rev Bras Farmacogn 14: 1-2.

Froelich S, Gupta MP, Siems K, Jenett-Siems K 2008. Phenylethanoid glycosides from Stachytarpheta cayennensis (Rich.) Vahl, Verbenaceae, a traditional antimalarial medicinal plant. Rev Bras Farmacogn 18: 517-520.

Furr M, Mahlberg PG 1981. Histochemical analyses of lacticifers and glandular trichomes in Cannabis sativa. J Nat Prod 44: 153-159.

Gorzalczany S, Sülsen V, Redko F, Vescina C, Muschietti L, Martino V,Acevedo C 2008. Choleretic and antispasmodic effects of Lippia integrifolia aqueous extract. Rev Bras Farmacogn 18: 16-20.

Hawaiian Ecosystems at Risk project (HEAR). http://www.hear. org/Píer/species/priva lappulacea.htm. Acessado em julho de 2006.

Jesus NZT, Lima JCS, Silva RM, Espinosa MM, Martins DTO 2009. Levantamentoetnobotânicodeplantaspopularmente utilizadas como antiúlceras e antiinflamatórias pela comunidade de Pirizal, Nossa Senhora do LivramentoMT, Brasil. Rev Bras Farmacogn 19: 130-139.

Johansen DA 1940. Plant Microtechnique. New York: McGrawHill.

Kobuski CE 1926. A Revision of the Genus Priva. Ann Missouri Bot Gard 13: 1-24 and 26-34.

Kraus JE, Arduin M 1997. Manual Básico de Métodos em Morfologia Vegetal. Seropédica, Edur.

Krauter D 1996. Mikrokosmos 85: 11-13.

Kunle O, Okogun J, Egamana E, Emojevwe E, Shok M 2003. Antimicrobial activity of various extracts and carvacrol from Lippia multiflora leaf extract. Phytomedicine 10: 59-61.

Leitão F, Fonseca-Kruel VS, Silva IM, Reinert F 2009. Urban ethnobotany in Petrópolis and Nova Friburgo (Rio de Janeiro, Brazil). Rev Bras Farmacogn 19: 333-342.

Mariath IR, Falcão HS, Barbosa-Filho JM, Sousa LCF, Tomaz ACA, Batista LM, Diniz MFFM, Athayde-Filho PF, Tavares JF, Silva MS, Cunha EVL 2009. Plants of the American continent with antimalarial activity. Rev Bras Farmacogn 19: 158-192.

Metcalfe CR, Chalk L 1972. Anatomy of the Dicotyledons. London: Oxford University Press.

Metcalfe CR, Chalk L 1988. Anatomy of the Dicotyledons Vol. 1. 2.ed. Oxford University Press, London.

Metz H 1961. Thin-layer chromatography for rapid assays of enzymic steroid transformations Naturwissenschaften 48: 569-570.

Mulert U 2001. Phylogenie der Verbenaceae: Kladistische Untersuchungen mit morphologischen und chemischen Merkmalen. Freiburg im Breisgau, 433p. Tese de doutorado- Fakultät für Chemie und Pharmazie der Albert-Ludwigs-Universität- Alemanha.

Neu R 1956. A New reagent for differentiating and determining flavones of paper chromatograms. Naturswissenschaften 43: 82 .

Oliveira FQ, Gobira B, Guimarães C, Batista J, Barreto M, Souza
M 2007. Espécies vegetais indicadas na odontologia. Rev Bras Farmacogn 17: 466-476.

Pérez S, Meckes M, Pérez M, Susunaga A, Zavala MA 2005. Antiinflammatory activity of Lippia dulcis. JEthnopharmacol 102: 1-4.

Quintans-Júnior LJ, Almeida JRGS, Lima JT, Nunes XP, Siqueira JS, Oliveira LEG, Almeida RN, Athayde-Filho PF, Barbosa-Filho JM 2008. Plants with anticonvulsant properties - a review. Rev Bras Farmacogn 18 (Supl.): 798-819.

Roberts EAH, Cartwright RA, Oldschool M 1957. Phenolic substances of manufactured tea. I. Fractionation and paper chromatography of water-soluble substances. $J \mathrm{Sci}$ Food Agr 8: 72-80.

Sarkar SK, Howarth RE 1976. Specifity of the vanillin test for flavonoids. J Agric Food Chem 24: 317-320.

Sass JE 1951. Botanical microtechnique. Iowa State College Press. Iowa.

Van Cotthem WRJ 1970. A classification of stomatal types. Bot J Linn Soc 63: 235-246.

Wagner H, Bladt S 1996. Plant drug analysis - A thin layerchromatography atlas. Springer. 2.ed. Munich. 